\title{
Sustainability in Manufacturing and Factories of the Future
}

\author{
Christoph Herrmann ${ }^{1, \#,}$, Christopher Schmidt', Denis Kurle', Stefan Blume', and Sebastian Thiede' \\ 1 Institute of Machine Tools and Production Technology, Technische Universität Braunschweig, Langer Kamp 19 b, 38106 Braunschweig, Germany \\ \# Corresponding Author / E-mail: c.herrmann@tu-braunschweig.de, TEL: +49-531-391-7149, FAX: +49-531-391-5842
}

KEYWORDS: Factory of the future, Sustainable manufacturing, Holistic factory, Paradigm change in manufacturing, Manufacturing trends

\begin{abstract}
An increasing global demand for natural resources and the inherent challenges accompanying this demand pose a great task for manufacturing companies. Apart from this, new technologies and a demographic change of the workforce as well as the desire for new individualized products make manufacturing more challenging than ever. To succeed in this new setting manifold perspectives of a factory have been proposed in order to enhance the understanding of the complex interdependencies between the factory elements. Against this background, this paper starts with a short overview regarding the paradigm change in manufacturing including contemporary trends triggering the requirements for factories of the future. Subsequent to that, a selection of factory perspectives is revised indicating the demand for a new holistic perspective of a factory that is more suitable with respect to the new trends. For that reason a new holistic perspective on the factory of the future is presented.
\end{abstract}

Manuscript received: May 28, 2014 / Accepted: July 9, 2014 (Invited Paper)

\section{Introduction}

History of the past two hundred years has proved that manufacturing is the foundation for global great powers. Due to its strong manufacturing sector, England rose in the 19th century to a global power, followed by the US, Germany, Japan and the USSR in the 20th. Hand in hand with the rise of power, manufacturing has been and still is the key factor for the development and prosperity of nations and thus for the growing wealth of the population. ${ }^{1,2}$ A prolonged, long-term economic growth cannot exist without machinery industry. Manufacturing of goods requires adequate production machinery whose components in turn have to be made by specific machine tools. Produced parts make their way not only into goods but also into new machine tools so that the technologies are used to reproduce new machines and thus contribute to the explosive economic growth of the last two hundred years. ${ }^{3}$ In 2013 , US\$ 18.3 trillion of world trade are allotted to merchandise exports while only US\$ 4.3 trillion fall upon commercial services. ${ }^{4}$ This shows the importance of the manufacturing sector for the global trade and, by the trade balance, for a country's wealth. Moreover, services can often not exist without manufactured goods. ${ }^{5,6}$

New markets are being developed in the emerging countries at which a significant share of value creation takes place locally. In parallel, an ongoing trend towards outsourcing and the emergence of sophisticated supply chains has allowed companies to use China, India and other low-wage countries as their elongated workbench. For over 100 years America was the world's leading manufacturer, whereas it is now neck and neck with China. Triggered by the financial crisis, some Western politicians started to reckon that it is time for their countries to go back to manufacturing goods in order to create jobs and to prevent more manufacturing skills from being lost. Most new and innovative products are introduced by manufacturing companies. Sticking to America as an example, the manufacturing sector makes up only about $11 \%$ of America's GDP, but it is responsible for $68 \%$ of domestic spending on research and development $^{7}$ and provides better-paid jobs, on average, than service industries. $^{8}$ As a source of innovation, manufacturing ensures the competitiveness of countries which is of special relevance to countries with high-tech sectors.

To keep or re-establish a strong manufacturing industry in a country, factories have to adapt to ever new challenges, trends and paradigms in manufacturing to stay competitive. This paper presents a review on the development of paradigms in manufacturing and assesses the extent to which established factory perspectives are able to depict the new trends. Based on a new factory model, ideas for the adaption of factories to the new trends are presented. 


\section{Review on the Development of Paradigms and New Trends in Manufacturing}

Over the last two centuries manufacturing industry has evolved through several paradigms from Craft Production over Mass Production to Lean Manufacturing and Mass Customization. ${ }^{9}$ This transformation process is still going on as production adopts to new trends.

Craft Production as the first paradigm responded to a specific customer order. Thus, products were unique and a high product variety and flexibility could be achieved. However, products were created at relatively high cost as no manufacturing systems were associated with this paradigm. ${ }^{10}$

Mass Production enabled the making of products at lower cost through large-scale manufacturing. However, the possible variety of products was very limited. Symbols for mass production were Henry Ford's moving assembly line and his statement: "Any customer can have a car painted any color that he wants so long as it is black". ${ }^{11}$ After the end of World War II demands for products were very high which allowed mass production to fully employ its strengths so that it reached a peak at that time. Mass production relies on three principles: The first, interchangeability, allows a random selection of parts for assembly. Parts are manufactured in large volumes with given tolerances so that economic volume effects were achieved. This was crucial to enable the second principle, the moving assembly line which was first introduced by Henry Ford in 1913. The moving assembly line brought the cars to the worker who performed the same task again and again which resulted in a significant improvement of speed and reduction of assembly costs. ${ }^{12}$ This division of labor is the third principle. The moving assembly line divided work with very fine granularity so that each worker could focus on some specialized repetitive tasks.

The Paradigm of Lean Manufacturing emerged after World War II as a necessity due to the limited resources in Japan. According to its developer it was called Toyota Production System. As a manufacturing management philosophy it focuses on minimizing all kinds of waste (Muda) along the value added chain while maximizing customer value. The Lean Management Philosophy is still an important part of all modern production systems. ${ }^{13}$

The fourth paradigm Mass Customization came up in the late 1980 's when the customer demand for product variety increased. Especially in the automotive industry, an enormous product variety has been achieved. To give an example, BMW claims that the number of possible combinations for the 7 Series alone could reach $1017 .{ }^{14}$ Again, three principles enable this paradigm. ${ }^{10}$ The first, family architecture, means that certain modules of a product are shared while others are provided with several variants. Their combination during assembly allows a high customization of the final product. ${ }^{15}$ Reconfigurable manufacturing systems as the second principle are a precondition to respond to the ever changing product mix and demands. They are designed to allow rapid adjustment of their production capacity, functionality, structure and control. An optimal configuration is the key driver for the system's performance. ${ }^{16,17}$ Principle three, the delaying differentiation, is a strategy to place the customer order decoupling point (the point where products take on their unique characteristics) as far as possible towards the end of the value added chain. Such delay supports cost minimization and respond time of the assembly system. $^{18,19}$ Nevertheless, this comes with a high manufacturing complexity which compromises system performance, especially when compared to mass production. ${ }^{20}$

The relationship between variety and the volume per model is displayed in Fig. 1 for the different paradigms. Obvious is a development towards smaller volumes per model and rising variety in the future. These new trends are described in the following.

Beyond mass customization there is a trend towards further individualized or personalized products. ${ }^{10}$ Highly customer-specific products may all have different work steps and cycle times. Thus, they cannot be restricted to static tact times of assembly lines anymore. Instead it is important, that - in the extreme case - lot size one can be manufactured under the same economical parameters as in large scale production systems although the production system's flexibility is much higher.

The increasing world population including aligning living standards on the one hand and the importance of fossil resources for energy production on the other hand result in rising energy- and resource prices. ${ }^{21}$ Governments establish regulations and regulative taxes to reduce emissions and to foster environmentally benign manufacturing. But also a growing demand of consumers for products with minimum environmental impact can be observed. ${ }^{22}$ Thus, a Sustainable production becomes a cornerstone of many manufacturing companies.

Several social aspects also influence manufacturing. Progressing urbanization ${ }^{23}$ with a concurrent desire for a reduction of commuting requires factories that can be integrated into residential areas as good neighbors to be close to both workers and customers. ${ }^{24}$ Having in mind the other trends, highly skilled professionals become even more important in the context of manufacturing as human factors, ${ }^{24-28}$ thus factories have to enable production-related learning and to simultaneously take living circumstances into account.

The progressing spread of information and communication technology (ICT) will further pervade the manufacturing sector. From the beginning in the 1950 's with first $\mathrm{NC}$ machines ${ }^{29}$ through computer controlled production cells in the late $60^{\prime} \mathrm{s}^{30}$ to the craze of computer

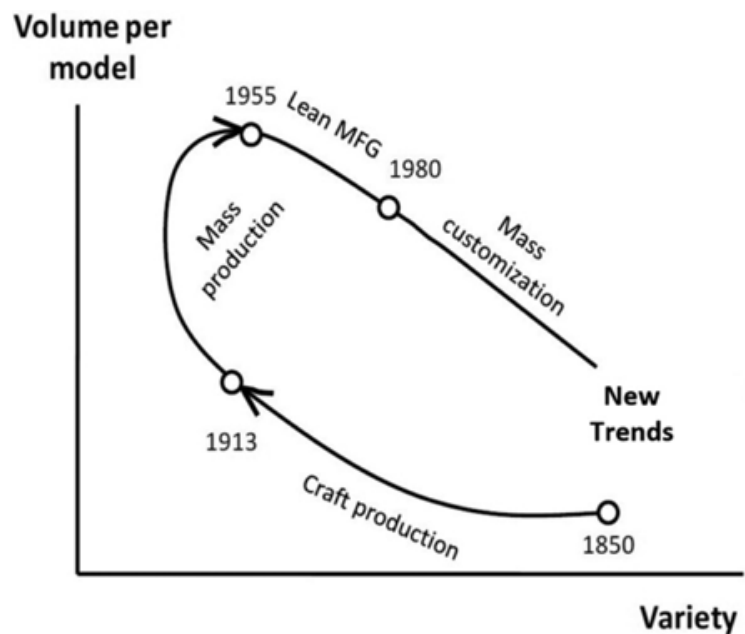

Fig. 1 Volume variety relationship in manufacturing paradigms (reproduced from Ref. 9 with permission) 
integrated manufacturing with its model of the manless factory ${ }^{31}$ a constant advancement is notable. As ICT components are getting cheaper, more versatile and more powerful they will find their way into new areas of production as indicated by the present research trends towards cyber physical systems (CPS). ${ }^{32}$

Production in spatial context implicates on the one hand a paradigm change from making factories less bad by just increasing their ecological efficiency to making them beneficial for their environment in the first place. Factories could play an important role in the smart grid or in the conditioning process of waste flows from surrounding (residential) areas. ${ }^{33,34}$ On the other hand, factories - and possibly also their product portfolio - could be further adapted to local constraints such as climate conditions or locally available resources. ${ }^{35}$ Thus, the topic of green manufacturing technologies has also been taking a prominent position in many research areas. ${ }^{36}$

\section{Holistic Factory Understanding and Current Factory Perspectives}

It has been widely acknowledged that improvements in manufacturing operations require a thorough understanding of a manufacturing system with the constituent interlinked elements and flows. ${ }^{37-39}$ Without having such an understanding in place the complexity and sophistication being involved in organizing a manufacturing system is only very difficult to manage. Therefore, a general understanding of a manufacturing system as a combination of production factors including typical input factors such as raw and auxiliary materials, semi-finished products, information, energy and space as well as typical output e.g. products, parts and waste has been anchored in people's mind with the help of different perspectives on manufacturing. ${ }^{40}$ To specify the general understanding, manufacturing can be subdivided into different levels of study as indicated by several researchers. ${ }^{39}$

Embracing this understanding the following remarks will primarily focus on the production factory (facility) level. Regarding this level, different perspectives on how to further understand a production factory have been proposed, see Fig. 2. These perspectives comprise varying system boundaries primarily from gate-to-gate. ${ }^{41,42}$

Within the gate-to-gate perspective, there exists a common consensus that a production factory composes three main partial systems: the technical building services (TBS), the building shell and the production system itself (with interlinked machines and personnel controlled through production management). ${ }^{43}$ Yet, the arrangement and presentation of these partial systems has been presented in several versions with various adaptations. This aspect is also shown in Fig. 2, where the upper two factory perspectives rather follow a peripheral and layered representation while the lower two visualize flows.

The first perspective in Fig. 2(a) subdivides a production factory and its processes into three peripheral orders centering the value adding production processes. The surrounding three peripheral orders are clustered according to their contribution to the value creation process having directly dependable subsystems placed on the first (e.g. direct energy and media supply for production machines), partly dependable

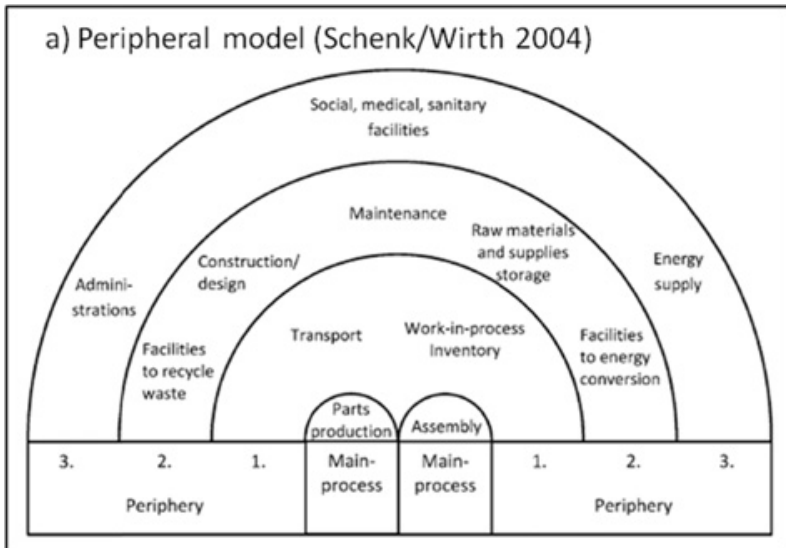

c) Production facility as a complex control system (Herrmann/Thiede 2009) local

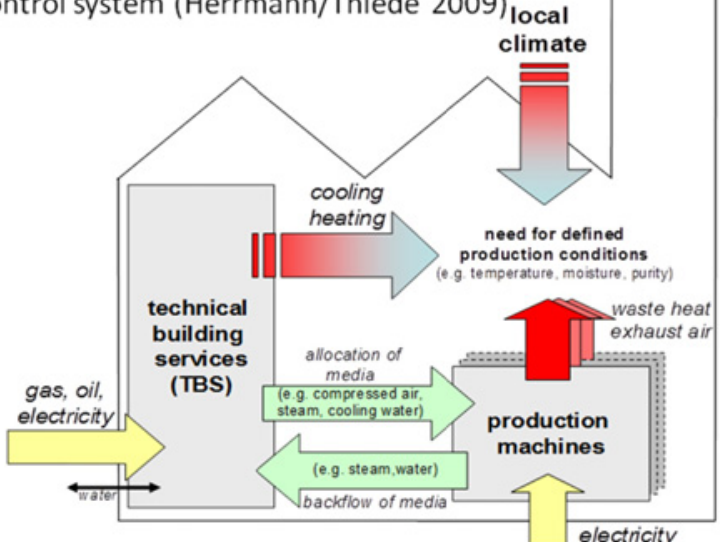

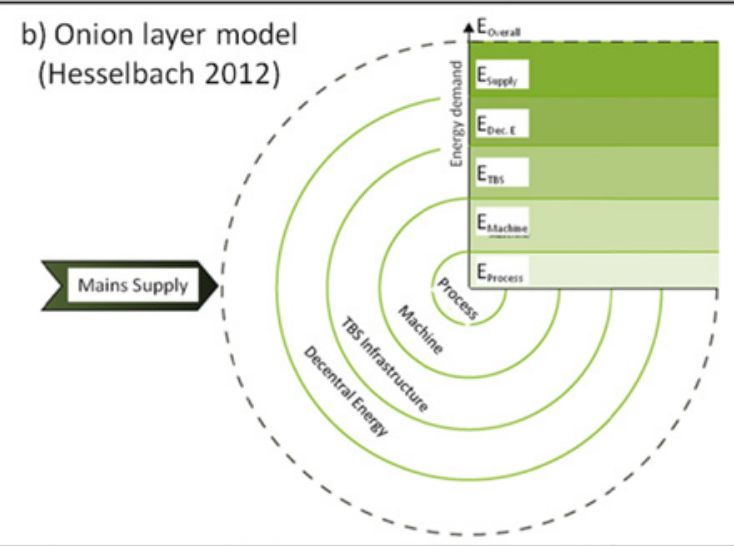

d) Manufacturing ecosystem model

(Depeisse et al. 2012)

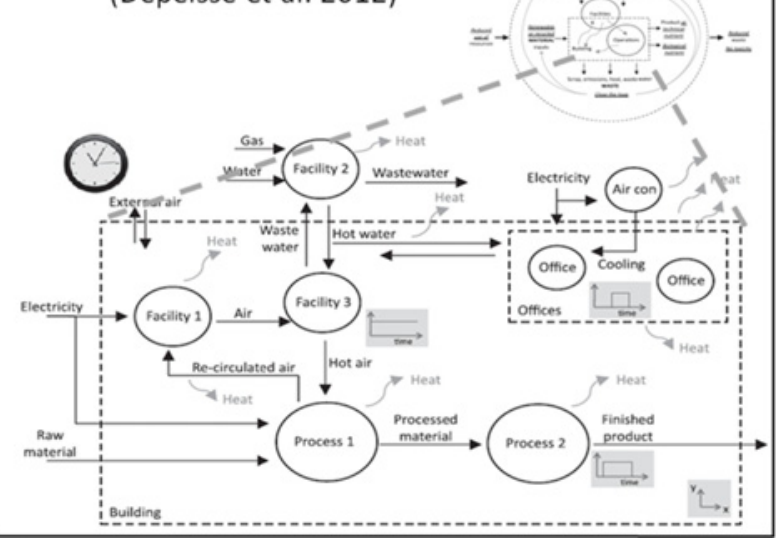

Fig. 2 Overview of current factory perspectives ${ }^{42-46}$ (reproduced from Ref. 42, Ref. 44, Ref. 46 with permission) 
subsystems located at the second (e.g. compressed air generation) and operating subsystems which have no direct effect on the value creation process arranged on the third periphery (e.g. HVAC, lighting). ${ }^{44,45}$ Another layered perspective is shown in Fig. 2(b) which follows the same understanding as the aforementioned peripheral perspective that production processes are the center elements of a production factory with certain core and cross-sectional technologies. Outside the production machines further cross-sectional technologies exist that support the value creation process. According to this layered factory perspective, optimization efforts should always start at the machine layer first and then continuously expand to the outer layers. ${ }^{46}$

The third perspective (see Fig. 2(c)) understands the orchestration of these three partial systems including their respective input and output flows as well as inherent dynamic interdependencies between them as a complex control system with internal and external influencing variables. $^{43}$

The fourth approach explores the emerging challenges when attempting to design a manufacturing facility with no or minimal environmental impact. This approach stresses that zero carbon manufacturing can only be achieved by broadening the current, rather linear input-output perspective of energy and media flows towards a more cyclic and interactive perspective, as shown in Fig. 2(d). ${ }^{41,42}$ By including such energy and media backflows, interactions between the respective partial systems can be made transparent revealing for instance appropriate adjustments when it comes to aligning certain conditioning activities such as defined temperature, pressure and purity. ${ }^{43}$ Besides that, potential interactions regarding new, alternative input and output flows between (sub)systems can be observed, considering traditional waste flows of one system or process as an input for another. ${ }^{41,42}$ This perspective applies for a single factory as well as a representation of a manufacturing ecosystem alike. ${ }^{42}$

To support revealing such interactions, different approaches have been followed, ranging from modelling approaches ${ }^{47}$ to the use of discrete event simulation, energy management systems and manufacturing execution systems each supporting the interaction between the three main partial systems. ${ }^{48,49}$

To give a broad overview of the previously selected and revised factory perspectives, Table 1 offers a comparison between these perspectives and several focuses of study which can be derived in a generalized form from the new trends in manufacturing as described in section 2. This comparative assessment indicates scopes with ensuing need for further research in a concise form. The compliance of each perspective with the identified requirements is evaluated by four general characteristics such as "fully considered" (O), "more considered" (@), "conditionally considered" ( $(\mathbf{O})$, "less considered" $(\bigcirc)$ and "not considered" $(\bigcirc)$.

As indicated by Table 1, there still exists a gap concerning contemporary trends in manufacturing and their representation by adequate factory perspectives encompassing all identified trends. Whereas a general production structure and environmental factors in form of energy and resource flows are yet widely considered to a certain extent, it seems that human factor, learning and social, symbiotic and spatial as well as ICT and CPS aspects are somewhat less pronounced compared to production and energy and resource flows in a factory context. ICT aspects for instance are primarily represented by the well-known automation pyramid which includes all relevant information levels ranging from field devices level (sensors/actuators) and programmable logic controller (PLC) level over process management as well as manufacturing execution systems (MES) level to the enterprise resource planning level as the highest relevant level for industrial manufacturing. ${ }^{50}$ Taking the aforementioned point into account underlines the fact that different perspectives and representations of the identified trends indeed exist, yet they have not been integrated into a new holistic factory perspective encompassing all of the respective trends and focuses of study listed in Table 1 .

\section{Paradigm Change towards a Holistic Factory of the Future}

The factory of the future needs to rapidly adapt to changing external requirements while aiming for a higher degree of sustainability. More than today, future production has to address all three dimensions of sustainability - economy, ecology and society. The economic perspective primarily demands for a higher profitability of manufacturing. From the ecological perspective the environmental impacts of production should be reduced, ${ }^{51}$ heading for zero emissions or even a positive influence of the factory on its local surroundings, improving the quality of air and water, exploiting local waste flows, providing renewable energies and acting as storage for surplus energy. From the social perspective the factory should serve as a place for people, focusing on collaborative learning and development of human capacities. Responding to these requirements and addressing the current trends described in section 2 and 3, a vision for a holistic factory of the future is presented in Fig. 3. It comprises four main aspects, which will be further explained in the following:

Table 1 Comparison of factory perspectives

\begin{tabular}{|c|c|c|c|c|c|c|}
\hline Focus of study: & $\begin{array}{c}\text { Schenk/ Wirth } \\
2004\end{array}$ & $\begin{array}{l}\text { Westkämper } \\
2006\end{array}$ & $\begin{array}{l}\text { Ball et al. } \\
2009\end{array}$ & $\begin{array}{l}\text { Herrmann/Thiede } \\
2009 \\
\end{array}$ & $\begin{array}{l}\text { Hesselbach } \\
2012 \\
\end{array}$ & $\begin{array}{c}\text { Depeisse et al. } \\
2012\end{array}$ \\
\hline Production structure & (1) & O & (1) & (1) & O & O \\
\hline Energy flows & (1) & $\mathrm{O}$ & $\theta$ & $\theta$ & (1) & \\
\hline Resource flows & O & $\bigcirc$ & (1) & (1) & $\mathrm{O}$ & (1) \\
\hline Human factor, learning and social aspects & O & $\bigcirc$ & $\bigcirc$ & $\bigcirc$ & $\bigcirc$ & $\bigcirc$ \\
\hline Symbiosis and spatial context & $\bigcirc$ & $\bigcirc$ & O & $\bigcirc$ & $\bigcirc$ & (1) \\
\hline ICT and CPS & $\bigcirc$ & $\bigcirc$ & $\bigcirc$ & $\bigcirc$ & $\bigcirc$ & $\bigcirc$ \\
\hline
\end{tabular}


1. Symbiotic flows \& urban integration of the factory

2. Adaptable factory elements: adaptive building shell, modular and scalable TBS, and flexible production system

3. Production cloud and cyber physical systems

4. Learning and training environments

\subsection{Symbiotic Flows \& Urban Integration}

Today's approaches of sustainable production primarily focus on efficiency, minimizing resource and energy input flows. ${ }^{42,52}$ This approach of minimization ultimately heads for zero emission goals. ${ }^{52}$ Although an efficiency strategy may appear as a good starting point for reducing environmental impacts of production, it's not an adequate long term solution, as it will remain only a strategy for damage management, but at the end it has to be stated that "less bad is not good". 53

Consequently, the factory of the future needs to head for metabolisms that enable materials to maintain their status as resources and increase value over time (upcycling of quality), generating a positive recoupling of the relationship between economy and ecology. This approach of eco-effectiveness contains closed-loop material and energy flows within the factory and a strong linkage with the external factory environment. In contrast to the efficiency approach, effectiveness starts with an assumption of a good production, which supports and regenerates ecological systems and enables long-term economic prosperity as depicted in Fig. $4 .^{52}$

An eco-effective production works similar to a biological system, where material flows serve as biological nutrients for living systems and "waste" does not exist. ${ }^{54}$ This idea of cyclical flows can even be further developed towards an inverted flow concept, compensating the imperfection in practical realisation of a cyclical flow system. Following the inverted flow approach industry uses already released emissions to ecosystem as inputs for industrial systems and hence for economic value creation. ${ }^{55}$

As seen in Fig. 3, the factory of the future will symbiotically share material and energy flows with industry, but also involve households and (urban) infrastructure to foster integration of smart grid technologies. Until now this vision of a symbiotic factory has already been rudimentarily established through so called industrial symbioses within eco-industrial parks, whose most popular realisation is situated in Kalundborg, Denmark. An overview about several other realized

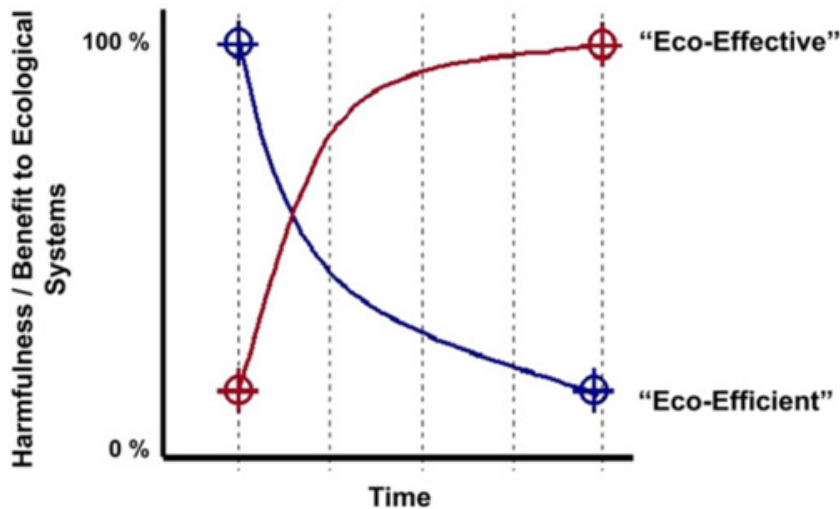

Fig. 4 Time dependant impacts of eco-efficiency and eco-effectiveness approaches $^{52}$ (reproduced from Ref. 52 with permission)

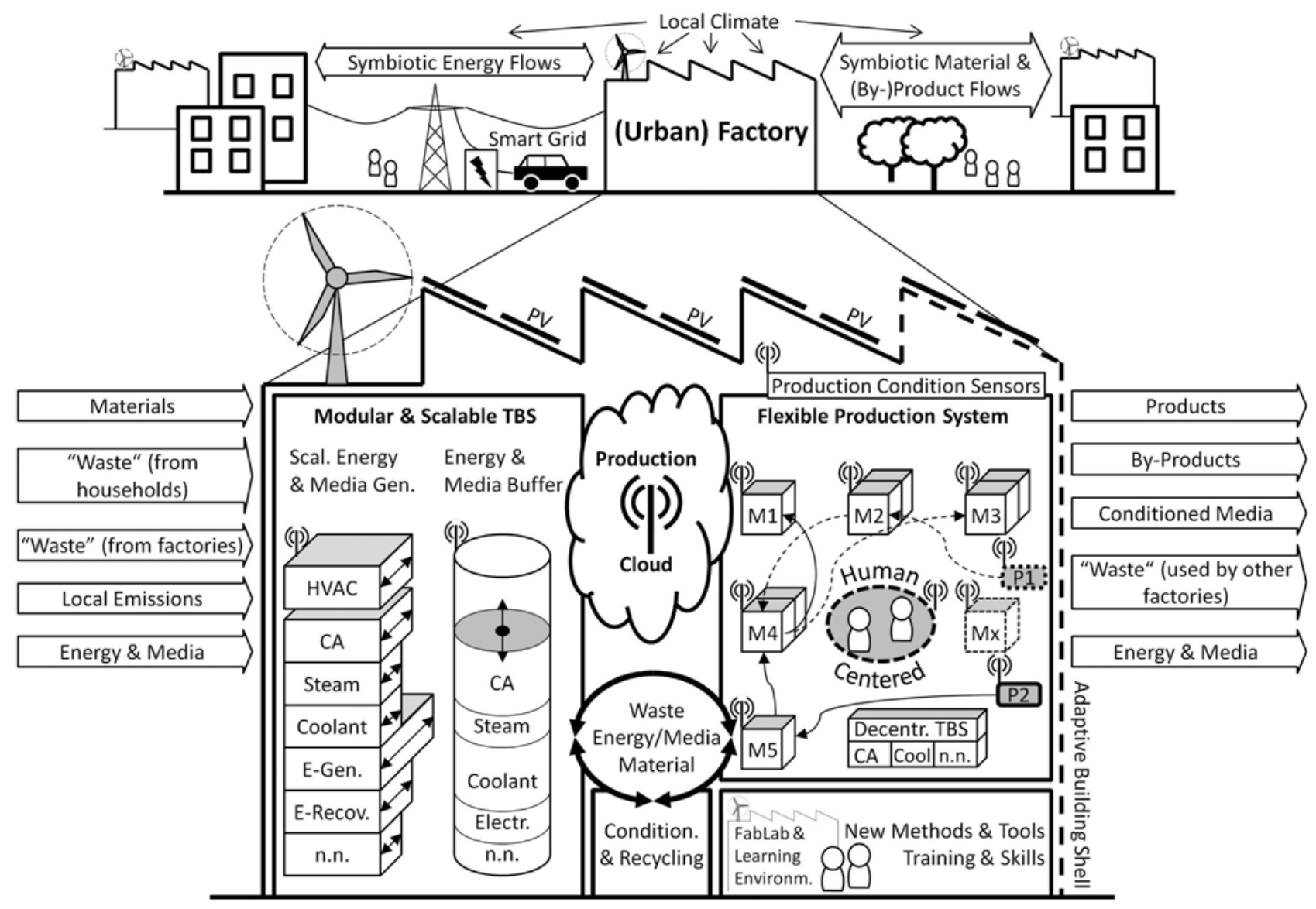

Fig. 3 Holistic understanding of a factory of the future 
projects is given by Chertow. ${ }^{56}$

The overall influence of the factory on its surroundings and the global environment will be positive; solid waste will be exploited and used for new products, wastewater will be treated, renewable energies will be produced or stored while neutralizing local emissions. These aspects allow the factory of the future to return to urban areas; recent projects linking residential areas with environmentally friendly manufacturing areas in the United States or Japan underpin this thesis. ${ }^{56}$

\subsection{Adaptable Factory Elements}

Amongst other drivers the strong linkage of material and energy flows with external infrastructure and the ability to successfully cope with the emerging trend of personalized products call for an appropriate and highly flexible physical factory infrastructure, including its building shell, TBS and production system. Wiendahl et al. give a broad overview about the way changeability of a factory can be realized. As fundamental enablers for a transformable system on factory level five principles have been identified, serving as a basis for the design of the described factory elements: ${ }^{57}$

- modularity,

- scalability,

- universality,

- compatibility and

- mobility.

\subsubsection{Adaptive Building Shell}

The building shell primarily serves as an insulation of the other factory elements from the outer conditions and the local climate respectively. Future requirements to the building shell regarding flexibility grow due to its importance for the changeability of the whole factory system, being significantly determined by the primary structure, e.g. the distance between the supporting columns of the building. For instance a distance of 30 to 40 meters between two pillars compared to a common distance of 20 meters allows much higher degrees of freedom in utilization for only little increased invests by approx. five percent. ${ }^{58}$ Such important properties of the building have to be defined in planning phase and are hardly changeable afterwards, that's why they limit the flexibility of a factory system on the long term. Hence the shell of a visionary factory of the future should be more adaptive to changing requirements, e.g. by realization of new building concepts. In this context approaches with an easy scalability may be the modular factory, the factory in containers, the factory within transportation systems (e.g. ship, train) or the factory in air-inflated structures. ${ }^{44,58}$

The building shell may also play an important role in positively influencing the local factory environment, e.g. through utilization of appropriate building materials like cement, cleaning the air by absorbing and photocatalytically decomposing various pollutants from the air. ${ }^{59}$

The roof area of a factory is predestined for the installation of renewable power plants, using energy of wind and sun. Conventional materials will be substituted by materials with integrated energy generation capabilities like BIPV (building-integrated photovoltaics), superseding retrofit solar power systems. ${ }^{60}$ In combination with energy storage solutions, this could allow for energy-self-sufficient plants, acting independently from the grid, which may be for instance favourable in rural areas of developing countries.

\subsubsection{Modular and Scalable TBS}

For enabling a production system to conduct value-adding manufacturing processes, TBS are usually needed, which pre-processes energy and media flows like electricity, compressed air, heat, cold, water and coolants depending on the required production conditions. ${ }^{43}$ In the factory of the future, the TBS will be linked physically but also virtually to the production system. TBS elements will be connected to a production condition monitoring system, automatically striving for optimal conditions regarding temperature, lighting, humidity etc.

As the factory of the future will be symbiotically linked to its environment, the TBS will play a major role in connecting inner and outer factory flows. So its tasks will not be limited to production supply but also consider external demands or supplies of energy and media. Thus energy and media buffers could be part of the system, balancing fluctuating inputs and outputs. Furthermore, they can also serve as stabilization for the electric grid, as backup for power blackouts and where necessary - to improve the power quality. ${ }^{61}$ As the factory will be part of a smart electricity grid, the adaption to fluctuating electrical energy production and demand will be of major concern. ${ }^{62}$ The balancing of electricity flows may be realised through central storages like battery systems or compressed air energy storages, but also through decentralized systems like electric vehicles or even products, i.e. producing more in times of high energy availability, contrary to current lean strategies heading for zero stocks. Furthermore the TBS must be able to react quickly to changing demands implied by fluctuating customer orders and a high degree of product individualisation, which leads to individual process chains with unequal energy and media demands.

Shortened product life cycles will also lead to more frequent reconstructions within the production system and the connected TBS. For this reasons a modular, expandable and partly decentralized TBS structure could be more suitable than traditional centralized systems, even if the degree of efficiency of small or decentralized systems may be lower. The design of TBS modules could follow the idea of plugand-produce, which has been derived from the plug-and-play principle of computing. ${ }^{63}$ Due to their high degree of hardware and software standardization, additional elements and devices can simply be plugged to machines, transport systems or TBS and start working instantly, like an USB device connected to a PC. Likewise they can be removed, if not needed anymore, enabling rapid adaptions to altering demands or requirements. An increased demand of compressed air after a reconstruction could for instance be faced with a plug-and-produce extension for the existing compressor, which therefore owns standardized interfaces. An over-dimensioning of systems could likewise be avoided, as upgrading and downgrading would be possible at all times with minor efforts.

\subsubsection{Flexible Production System}

A flexible production system within a factory of the future responds to the increasing variety and complexity of future products, which need to be produced with low costs and low environmental impacts. A high profitability and minimal consumption of resources within the production system can be fostered by a high degree of machine utilisation. But especially for assembly operations, traditional concepts are not able to maintain an optimal utilization of machines while 
producing components with a high variance in processing times on the same production line. ${ }^{64}$ Determined by the different work contents, every variant causes different processing times, hence equal cycle times for all products and processes are not reasonable. In conclusion, traditional production lines are unsuitable to respond to future requirements in terms of flexible assembly. A promising solution could be an increased versatility of the production machines, allowing every machine to assemble a big variety of different product variants. Products may not all take the same way through production, but search for an time optimized path, depending on free resources and leading to reduced overall waiting times of machines as well as reduced lead times. This approach would also necessitate an appropriate flexible transport system, allowing an individual distribution of material to the production resources.

The flexible production system also features a high degree of scalability to respond to changing market demands. Therefore the design of production resources, in particular the machines, may follow the plug-and-produce philosophy. ${ }^{63}$

The multi-agent system (MAS) approach, which bases upon a set of distributed autonomous but cooperative entities, may be implemented to operate the production system. ${ }^{65}$ As appropriate information flows are essential for operation, most elements of the system will be equipped with sensors and empowered to communicate. Many decisions then can be made decentralized and collaboratively by the agents, resulting in an optimized performance of the whole production system. This approach also facilitates a quick reconfigurability of the system, because no fixed central systems for production planning and control have to be changed.

Beneath all technical aspects, human employees shall still be in the center of the production system, as they will be needed in all phases of factory operations from the planning through operation to maintenance and repair. ${ }^{50}$ Human cognitive and sensomotor abilities should be used and systematically developed, e.g. using learning and training environments (see section 4.4), while technology should support human actions. Therefore, technology has to be adjusted to human needs instead of a conversely adaption of human action to technological constraints. Technological possibilities will also lead to a higher level of mobility for human employees (e.g. working from places outside the factory), as all relevant information will be available through ICT anywhere at any time.

\subsection{Production Cloud and Cyber Physical Systems}

As information technology will further spread over all factory layers, including a broad application of sensors on shop floor level, the collection, consolidation and processing of information on a higher level will be reasonable, even if decisions will be taken decentralized by independent agents. For instance, CPS will assist human workers on shop floor level by providing appropriate live information collected from the production system, which will be preprocessed for the specific task.

The huge amount of data collected in the factory of the future requires the setup of a decentralized data pool, referred to as "production cloud", collecting and processing all information from the production system and TBS. This includes data regarding productivity (e.g. processing and cycle times), energy and resources (e.g. energy demands per process, machine, part), product related information (e.g. product quality indicators) or data concerning the production conditions (temperature, humidity, lighting etc.) as well as the current status of all elements like machines and products of the factory. This idea is closely linked to the concept of an Internet of Things (IoT), which was introduced in the 1990 's. ${ }^{66,67}$ In the IoT, all physical elements also possess a virtual representation in an internet like structure. This virtual representation requires an installation of a broad physical network of sensors, actuators and processors including a distinct identifiability of all objects, e.g. realized by integration of RFID tags. Such a vision of a Factory of Things, composed of self-organizing smart objects without a traditional hierarchy, is also often referred to as Smart Factory. ${ }^{50}$

Based on the virtual representation of physical elements, the production cloud does also contain key elements of a Digital Factory, which can be understood as a virtual depiction of the real factory, used to predict and improve future system behavior through appropriate simulation techniques. According to VDI $4499^{68}$ this concept contains "a comprehensive network of digital models and methods, including simulation and $3 \mathrm{D}$ visualization. Its purpose is the integrated planning, implementation, control and on-going improvement of all important factory processes and resources relating to the product".

The storage and processing of all data in a cloud entails several advantages like a high degree of transparency through embedded monitoring and control functions, constituting an important premise for improvement measures. The production cloud could also serve as a link to cloud manufacturing services, ${ }^{69}$ which appears to be an adequate approach for the manufacturing of individualized products within virtual manufacturing networks. Every factory of the network can offer its services with regard to free capacity, deliverable quality or achievable delivery times, causing individual supply chains for every product or variant.

\subsection{Learning and Training Environments}

Despite all technological progress, human abilities will still be one of the key success factors of future factories. Highly skilled and educated employees will be needed, who have to be trained continuously to keep pace with changing external requirements and technological improvements. In this context, Learning Factories (also referred to as Teaching Factories) could play an essential part in training and teaching, as they provide experimental and research environments including realistic production processes. ${ }^{70}$ Typically they can be used and adjusted for teaching purposes of different target groups and allow for the communication and testing of theoretical knowledge in practical application; learning results can be transferred easily to work in a real factory environment. A Learning Factory can be both physical and digital. Physical environments comprise real system components like machines, assembly, logistics, information and energy flow modules while the digital environments include planning, modelling, visualization and simulation tools. Digitally created solutions can be tested, evaluated and demonstrated in the physical learning environment. ${ }^{71}$ For several years Learning Factories have now been established in academic research, but also in industry an increasing implementation can be observed.

The factory of the future may also contain fabrication laboratories or "FabLabs", comprising a collection of tools for design and modelling, prototyping and fabrication, instrumentation, testing, debugging and documentation for a wide range of applications. ${ }^{72,73}$ 
People will be enabled to design and physically realize their highly personalized own product creations in the FabLab, using the provided infrastructure like rapid manufacturing machines. This approach may be highly beneficial especially in regions with lower education or prosperity, supporting regional development by catering specific individual needs of the population. Likewise, FabLabs also offer a platform for knowledge transfer to broad parts of society in industrial nations. Many of today's implemented FabLabs participate in the global FabLab network and act according to the international Fab Charter, highlighting the ideas of sharing knowledge, collaboration across borders and open access to ideas and inventions. ${ }^{74}$

\section{Conclusions}

Manufacturing is a main factor for the prosperity of nations and an essential source of innovation and development. To ensure the competitiveness of manufacturing industry, factories have always needed to adapt to new challenges and trends, resulting in several changes of manufacturing paradigms over the last two centuries. Today's and future factories also face several evolving trends like customers demanding for highly personalized products, the necessity for an eco-friendly production reducing its environmental impacts, an increasing importance of social aspects including the requirements of production-related learning, a still lasting technology push regarding ICT as well as the need for an improved integration of factories to their spatial context. A thorough understanding of a factory system is a premise for the ability to respond to those challenges. The described holistic factory perspective closes an existing gap concerning the contemporary trends in manufacturing and their representation by adequate factory perspectives. The presented vision comprises four main aspects, starting with the symbiotic integration of the factory to its surroundings and in particular to urban or domestic areas as well as an orientation towards eco-effectiveness, heading for a positive recoupling between economy and ecology. Regarding the factory infrastructure a higher degree of flexibility is needed, represented by the adaptive properties of the main factory elements building shell, TBS and production system. The operation of such a system is only feasible by means of a decentralized collection and usage of information as proposed with the production cloud concept. A broad application of ICT is indispensable, whereat CPS play a major role linking the real and virtual factory world. As human skills and abilities still constitute a central aspect of future factories, learning and training further gain in importance, necessitating specific learning environments like Learning Factories. The factory of the future therefore responds to the identified challenges by addressing all three dimensions of sustainability, moving from today's rather economical focus towards ecological and social strategies.

\section{REFERENCES}

1. Gutowski, T. G., Allwood, J. M., Herrmann, C., and Sahni, S., "A Global Assessment of Manufacturing: Economic Development, Energy Use, Carbon Emissions, and the Potential for Energy Efficiency and Materials Recycling," Annual Review of Environment and Resources, Vol. 38, pp. 81-106, 2013.
2. Reinert, E. S., "How Rich Countries Got Rich ... and Why Poor Countries Stay Poor,” Constable London, pp. 77-151, 2007.

3. Roosevelt Institute, "Six Reasons Manufacturing is Central to the Economy," http://www.rooseveltinstitute.org/new-roosevelt/six-reasonsmanufacturing-central-economy (Accessed 20 April 2014)

4. World Trade Organization, "World Trade Report 2013," http:// www.wto.org/english/res_e/publications_e/wtr13_e.htm (Accessed 20 April 2014)

5. Aurich, J. C. and Clement, M. H., "Produkt-Service Systeme," Springer-Verlag Berlin Heidelberg, pp. 137-140, 2010.

6. Kuntzky, K., "Systematische Entwicklung von Produkt-Service Systemen," Vulkan Verlag, p. 18ff, 2013.

7. The Economist, "Back to Making Stuff," http://www.economist.com /node/21552899 (Accessed 20 April 2014)

8. Helper, S. and Wial, H., "Strengthening American Manufacturing: A New Federal Approach," Metropolitan Policy Program at Brookings, pp. 4-6, 2010.

9. Hu, S. J., Ko, J., Weyand, L., ElMaraghy, H., Lien, T., et al., "Assembly System Design and Operations for Product Variety," CIRP Annals-Manufacturing Technology, Vol. 60, No. 2, pp. 715733, 2011.

10. Hu, S. J., "Evolving Paradigms of Manufacturing: From Mass Production to Mass Customization and Personalization," Procedia CIRP, Vol. 7, pp. 3-8, 2013.

11. Henry, F. and Samuel, C., "My Life and Work, Garden City," Garden City Publishing Company, Inc., p. 71, 1922.

12. EyeWitness to History "Henry Ford Changes the World, 1908," http:// www.eyewitnesstohistory.com/ford.htm (Accessed 30 July 2014)

13. Jones, D. T., Roos, D., and Womack, J. P., "Machine That Changed the World," Simon and Schuster, p. 64ff, 1990.

14. BMW Group, "Wie ein Fahrzeug Entsteht," http://www.bmwgroup. com/bmwgroup_prod/d/0_0_www_bmwgroup_com/produktion/fahr zeugfertigung/automobilfertigung/erlebnis_produktion/prod_prozesse .shtml (Accessed 20 April 2014)

15. Tseng, M. M., Jiao, J., and Merchant, M. E., "Design for Mass Customization," CIRP Annals-Manufacturing Technology, Vol. 45, No. 1, pp. 153-156, 1996.

16. Koren, Y., Heisel, U., Jovane, F., Moriwaki, T., Pritschow, G., et al., "Reconfigurable Manufacturing Systems," CIRP AnnalsManufacturing Technology, Vol. 48, No. 2, pp. 527-540, 1999.

17. Koren, Y., Hu, S. J., and Weber, T. W., "Impact of Manufacturing System Configuration on Performance," CIRP AnnalsManufacturing Technology, Vol. 47, No. 1, pp. 369-372, 1998.

18. Lee, H. L. and Tang, C. S., "Modelling the Costs and Benefits of Delayed Product Differentiation," Management Science, Vol. 43, No. 1, pp. 40-53, 1997. 
19. Ko, J. and Jack Hu, S., "Balancing of Manufacturing Systems with Complex Configurations for Delayed Product Differentiation," International Journal of Production Research, Vol. 46, No. 15, pp. 4285-4308, 2008.

20. Hu, S., Zhu, X., Wang, H., and Koren, Y., "Product Variety and Manufacturing Complexity in Assembly Systems and Supply Chains," CIRP Annals-Manufacturing Technology, Vol. 57, No. 1, pp. 45-48, 2008.

21. Herrmann, C., "Ganzheitliches Life Cycle Management," SpringerVerlag Berlin Heidelberg, p. 30, 2010.

22. Li, W., "Energy and Eco-Efficiency of Manufacturing Processes," Ph.D. Thesis, Mechanical \& Manufacturing Engineering, Faculty of Engineering, University of New South Wales, p. 1, 2012.

23. The World Bank, "Developing Countries Need to Harness Urbanization to Achieve the MDGs: IMF-World Bank Report," http:/www.worldbank.org/en/news/press-release/2013/04/17/developing -countries-need-to-harness-urbanization-to-achieve-mdgs-imf-worldbank-report (Accessed 20 April 2014)

24. European Commission, "Factories of the Future. Multi-Annual Roadmap for the Contractual PPP under Horizon 2020," European Union, p. 30, 2013.

25. Spiegel, "Milliardenschäden: Industrie beklagt dramatischen Fachkräftemange,” http://www.spiegel.de/wirtschaft/milliardenschaeden -industrie-beklagt-dramatischen-fachkraeftemangel-a-520142.html (Accessed 20 April 2014)

26. Deutsche Industrie- und Handelskammertag e.V., "DIHK Mittelstandsreport," http://www.dihk.de/presse/meldungen/2011-0815-mittelstandsreport (Accessed 31 July 2014)

27. VDI Nachrichten, "Aus Sicht der Industrie ist der Fachkräftemangel spür- und sichtbar," http://www.vdi-nachrichten.com/ManagementKarriere/Aus-Sicht-Industrie-Fachkraeftemangel-spuer-sichtbar (Accessed 20 April 2014)

28. Damodaran, L., "Human Factors in the Digital World Enhancing Life Style - The Challenge for Emerging Technologies," International Journal of Human-Computer Studies, Vol. 55, No. 4, pp. 377-403, 2001.

29. Pease, W., "An Automatic Machine Tool," Scientific American, Vol. 187, No. 3, pp. 101-115, 1952.

30. Talavage, J. and Hannam, R. G., "Flexible Manufacturing Systems in Practice: Design, Analysis, and Simulation," CRC Press, pp. 4548, 1987.

31. Mitchell Jr, F., "Cim Systems: An Introduction to ComputerIntegrated Manufacturing," Prentice-Hall, 1991.

32. European Comission, "Call for Factories of the Future: Process Optimisation of Manufacturing Assets," http://ec.europa.eu/research/ participants/portal/desktop/en/opportunities/h2020/topics/2180-fof01-2014.html (Accessed 20 April 2014)

33. Chertow, M. R., ““'Uncovering” Industrial Symbiosis,” Journal of
Industrial Ecology, Vol. 11, No. 1, pp. 11-30, 2007.

34. Greenpeace, "Energy [R]Evolution: A Sustainable World Energy Outlook," http://www.greenpeace.org/international/Global/international/ publications/climate/2012/Energy\%20Revolution\%202012/ER2012.pdf (Accessed 31 July 2014)

35. Hesselbach, J. and Herrmann, C., "Glocalized Solutions for Sustainability in Manufacturing," Proc. of the CIRP International Conference on Life Cycle Engineering, Springer, p. v, 2011.

36. Ahn, S.-H., "An Evaluation of Green Manufacturing Technologies based on Research Databases," Int. J. Precis. Eng. Manuf.-Green Tech., Vol. 1, No. 1, pp. 5-9, 2014.

37. ICT Consultation Group, "ICT and Energy Efficiency: The Case for Manufacturing, European Commission,” pp. 20-27, 2009.

38. Corinne, R. W., Athulan, V., and David, D., "Appropriate Use of Green Manufacturing Frameworks," Proc. of the 17th CIRP Life Cycle Engineering Conference, pp. 196-201, 2010.

39. Duflou, J. R., Sutherland, J. W., Dornfeld, D., Herrmann, C., Jeswiet, J., et al., "Towards Energy and Resource Efficient Manufacturing: A Processes and Systems Approach," CIRP AnnalsManufacturing Technology, Vol. 61, No. 2, pp. 587-609, 2012.

40. Westkämper, E., "Einführung in die Organisation der Produktion," Springer Berlin Heidelberg, pp. 195-196, 2006.

41. Ball, P. D., Evans, S., Levers, A., and Ellison, D., "Zero Carbon Manufacturing Facility-towards Integrating Material, Energy, and Waste Process Flows," Proc. of the Institution of Mechanical Engineers, Part B: Journal of Engineering Manufacture:, Vol. 223, No. 9, pp. 1085-1096, 2009.

42. Despeisse, M., Ball, P. D., Evans, S., and Levers, A., "Industrial Ecology at Factory Level-A Conceptual Model," Journal of Cleaner Production, Vol. 31, pp. 30-39, 2012.

43. Herrmann, C. and Thiede, S., "Process Chain Simulation to Foster Energy Efficiency in Manufacturing," CIRP Journal of Manufacturing Science and Technology, Vol. 1, No. 4, pp. 221-229, 2009.

44. Schenk, M., Wirth, S., and Müller, E., "Fabrikplanung und Fabrikbetrieb: Methoden für die wandlungsfähige und vernetzte Fabrik," Springer-Verlag Berlin Heidelberg, $2^{\text {nd }}$ Ed., pp.137-138, 2014.

45. Müller, E., Engelmann, J., Löffler, T., and Strauch, J., "Energieeffiziente Fabriken planen und betreiben," Springer Berlin Heidelberg, pp. 43-47, 2009.

46. Hesselbach, J., "Energie- und klimaeffiziente Produktion," Springer Berlin Heidelberg, pp. 14-15, 2012.

47. Heilala, J., Vatanen, S., Tonteri, H., Montonen, J., Lind, S., et al., "Simulation-based Sustainable Manufacturing System Design," Proc. of the WSC Simulation Conference, pp. 1922-1930, 2008.

48. Michaloski, J. L., Shao, G., Arinez, J., Lyons, K., Leong, S., and Riddick, F., "Analysis of Sustainable Manufacturing using 
Simulation for Integration of Production and Building Service," Proc. of the Symposium on Simulation for Architecture and Urban Design, pp. 93-101, 2011.

49. Thiede, S., Seow, Y., Andersson, J., and Johansson, B., "Environmental Aspects in Manufacturing System Modelling and simulation-State of the Art and Research Perspectives," CIRP Journal of Manufacturing Science and Technology, Vol. 6, No. 1, pp. 78-87, 2013

50. Zuehlke, D., "Smartfactory-towards a Factory-of-Things," Annual Reviews in Control, Vol. 34, No. 1, pp. 129-138, 2010.

51. Dornfeld, D. A., "Moving Towards Green and Sustainable Manufacturing,” Int. J. Precis. Eng. Manuf.-Green Tech., Vol. 1, No. 1, pp. 63-66, 2014.

52. Braungart, M., McDonough, W., and Bollinger, A., "Cradle-toCradle Design: Creating Healthy Emissions-A Strategy for EcoEffective Product and System Design," Journal of Cleaner Production, Vol. 15, No. 13, pp. 1337-1348, 2007.

53. Berkhout, P. H., Muskens, J. C., and Velthuijsen, J. W., "Defining the Rebound Effect,” Energy Policy, Vol. 28, No. 6-7, pp. 425-432, 2000.

54. Ayres, R. U. and Simonis, U. E., "Industrial Metabolism: Restructuring for Sustainable Development," United Nations University Press, p. 6, 1994.

55. Despeisse, M., Ball, P. D., and Evans, S., "Strategies and Ecosystem View for Industrial Sustainability," in: Re-Engineering Manufacturing for Sustainability, Nee, A. Y., Song, B., and Ong, S. K.,(Eds.), Springer Singapore, pp. 565-570, 2013.

56. Chertow, M. R., "Industrial Symbiosis: Literature and Taxonomy," Annual Review of Energy and the Environment, Vol. 25, No. 1, pp. 313-337, 2000.

57. Wiendahl, H.-P., ElMaraghy, H. A., Nyhuis, P., Zäh, M. F., Wiendahl, H.-H., et al., "Changeable Manufacturing-Classification, Design and Operation," CIRP Annals-Manufacturing Technology, Vol. 56, No. 2, pp. 783-809, 2007.

58. Wiendahl, H.-P., Nofen, D., Klußmann, J. H., and Breitenbach, F., "Planung modularer Fabriken," Hanser München, 2005.

59. Chen, J. and Poon, C.-S., "Photocatalytic Construction and Building Materials: From Fundamentals to Applications," Building and Environment, Vol. 44, No. 9, pp. 1899-1906, 2009.

60. Eiffert, P. and Kiss, G. J., "Building-Integrated Photovoltaic Designs for Commercial and Institutional Structures: A Sourcebook for Architects,” DIANE Publishing, pp. 67-68, 2000.

61. Eyer, J. and Corey, G., "Energy Storage for the Electricity Grid: Benefits and Market Potential Assessment Guide," Sandia National Laboratories, pp. 69-73, 2010.

62. Masaud, T. M., Lee, K., and Sen, P. K., "An Overview of Energy Storage Technologies in Electric Power Systems: What is the Future?" Proc. of the IEEE in North American Power Symposium, pp. 1-6, 2010.
63. Hildebrand, T., Mäding, K., and Günther, U., "Plug+ Produce: Gestaltungsstrategien für die wandlungsfähige Fabrik," IBF Chemnitz, 2005.

64. Krajewski, L. J., Ritzman, L. R., and Malhotra, M. K., “Operations Management, Processes and Supply Chains," Upper Saddle River, $9^{\text {th }}$ Ed., 2010.

65. Wooldridge, M., "An Introduction to Multi-Agent Systems," John Wiley \& Sons, pp. 223-249, 2002.

66. Weiser, M., "The Computer for the 21st Century," Scientific American, Vol. 265, No. 3, pp. 94-104, 1991.

67. Ashton, K., "That 'Internet of Things' Thing," RFiD Journal, Vol. 22, pp. 97-114, 2009.

68. VDI No. 4499 Blatt 1, "Digitale Fabrik - Grundlagen,” 2008.

69. Tao, F., Zhang, L., Venkatesh, V., Luo, Y., and Cheng, Y., "Cloud Manufacturing: A Computing and Service-Oriented Manufacturing Model," Proc. of the Institution of Mechanical Engineers, Part B: Journal of Engineering Manufacture, Vol. 225, pp. 1969-1976, 2011.

70. Chryssolouris, G., Mavrikios, D., and Mourtzis, D., "Manufacturing Systems: Skills \& competencies for the Future,” Procedia CIRP, Vol. 7, pp. 17-24, 2013.

71. Wagner, U., AlGeddawy, T., ElMaraghy, H., and Müller, E., "The State-of-the-Art and Prospects of Learning Factories," Procedia CIRP, Vol. 3, pp. 109-114, 2012.

72. Gershenfeld, N., "How to Make Almost Anything: The Digital Fabrication Revolution,” Foreign Affairs, Vol. 91, p. 58, 2012.

73. Mikhak, B., Lyon, C., Gorton, T., Gershenfeld, N., McEnnis, C., and Taylor, J., "Fab Lab: An Alternate Model of ICT for Development," Proc. of the International Conference on Open Collaborative Design for Sustainable Innovation, 2002.

74. The International Fab Lab Association, "The Fab Charter," http:// www.fablabinternational.org/fab-lab/the-fab-charter (Accessed 31 July 2014) 